\title{
EL COMPROMISO DESPUÉS DEL COMPROMISO. POESÍA, DEMOCRACIA Y GLOBALIZACIÓN (1980-2005) (EXTRACTO)
}

The engagement after the engagement. Poetry, democracy and globalization (1980-2005) (Extract)

\author{
ARACELI IRAVEDRA \\ UNIVERSIDAD DE OVIEDO (ESPAÑA) airavedra@uniovi.es
}

RECIBIDO: 11 DE JULIO DE 2018

ACEPTADO: 11 DE JULIO DE 2018

RESUMEN: En la escena poética de fin del siglo XX, un nutrido conjunto de voces ha vuelto a interrogarse sobre el sentido del binomio literatura-compromiso, reabriendo el debate en torno a un asunto que parecía cancelado por las conquistas democráticas y la condición escéptica de la posmodernidad. Se trata de una serie de propuestas que, desde planteamientos estéticos a veces enfrentados, colabora en la elaboración de respuestas, o siquiera de incómodas preguntas, ante las urgencias del espacio público originadas por el nuevo escenario de la globalización, las contradicciones del capitalismo postindustrial y las presiones homologadoras de la sociedad contemporánea. A la luz de un corpus significativo de poéticas, que postulan modos diversos de encarar las relaciones entre poesía, historia, ideología o política, este trabajo persigue aquilatar el significado y los matices que en la coyuntura de entresiglos ha ido tomando la noción histórico-literaria de compromiso. Una noción que, por un lado, se encarna en discursos poéticos retóricamente heterogéneos; y, por otro, acusa una visible renovación de sus fundamentos teóricos, y de sus ideales formales y temáticos, que autoriza a hablar de un compromiso después del compromiso, al romper con algunas de sus claves más arraigadas e instaurar una quiebra con los modelos históricos más emblemáticos.

PALABRAS ClaVE: Poesía, compromiso, entresiglos, democracia, globalización

\begin{abstract}
In the poetic scenery at the turn of the 20th century, a nourished group of voices has started to interrogate again about the sense of the duality literature-commitment, reopening the debate surrounding an issue that seemed cancelled by the democratic achievements and the skeptical condition of postmodernism. It involves a set of proposals that, from esthetical approaches that sometimes clash with each other, collaborates in the elaboration of answers, or even of uncomfortable questions, against the urgencies of public space originated by the new scenario of globalization, the contradictions of postindustrial capitalism and the reviewing pressures of contemporary society. In the light of a significant corpus of poetics, that postulate different ways of facing the relationships between poetry, history, ideology or politics, this paper pretends to refine the meaning and the nuances that the historical-literary notion of commitment has developed between the centuries. A notion that, on one hand, it incarnates in rhetorically heterogeneous poetical speeches; and on the other hand, shows a visible renovation of its theorical fundamentals, and of its formal and thematic ideals, which authorizes to talk about a commitment after the commitment, since it breaks with some of its most rooted keys and establishes a collapse with the most emblematic historic models.
\end{abstract}

KEYWORDS: Poetry, Engagement, End of Century, Democracy, Globalization.

Iravedra, Araceli

“El compromiso después del compromiso. Poesía, democracia y globalización (1980-2005)”.

Kamchatka. Revista de análisis cultural 11 (Julio 2018): 39-55

DOI: 10.7203/KAM. 11.12743 ISSN: 2340-1869

Monográfico LECTURAS DEL DESIERTO: NUEVAS PROPUESTAS POÉTICAS EN ESPAÑa 


\section{TODAVÍA EL COMPROMISO ${ }^{1}$}

No sería extraño que el rótulo que cobija este libro hubiera suscitado en el lector una mueca irreprimible de contrariedad, al poner una vez más ante sus ojos una reflexión sobre literatura y compromiso. La contrariedad, seguramente, continúa siendo hoy la reacción más común de lectores y escritores ante la interpelación sobre el sentido actual de este binomio siempre inquietante, pero que parece conducir pese a todo a un debate intelectual tan manido ya como enojoso, tan irritante como pasado de moda. Sobre lo fastidioso de la pregunta ironizaba recientemente un observador perspicaz y autorizado, a quien la noción de compromiso se le antojaba un "fantasma" infatigable que venía recorriendo la poesía contemporánea, que una vez y otra se le aparecía poniendo al escritor -tentado de darle la espalda- con demasiada frecuencia en el trance impertinente de interrogarse, de palparse la ropa y hasta de ceder al diálogo con elementos de entrada tan espurios como la sociedad, la historia o la política (García, 2006: 25). A lo enfadoso del debate, a su desfase y al cansancio que genera en la comunidad literaria han aludido también los creadores, al sospechar, por ejemplo, que la palabra "social" nos pone a la mayoría al borde del desaliento y de la deserción más inmediata, suena a cosa pasada y putrefacta, es un pésimo reclamo que no logra arrancar sino bostezos y cuyo descrédito, en fin, exige buenas dosis de valor para atreverse a convocarla en un poema (Vallvey, 2000: 18). "Poesía social", "poesía comprometida" o "poesía política" son etiquetas hoy desprestigiadas, sostiene asimismo otro implicado, quien lamenta la espontánea e instintiva prevención que nos conduce a torcer el gesto al escuchar sintagmas tan injusta como comprensiblemente asimilados a "retórica vacua, maniqueísmo, dogmatismo o ingenuidad" (Montero, 2003: 6). Así podríamos continuar enumerando observaciones que dan cuenta de un mayoritario estado de opinión que, en el contexto literario español, tiene una evidente razón de ser histórica. Y, sin embargo, para enlazar con una reciente reflexión de Luis García Montero,

tal vez las reapariciones de temas pasados de moda, la actualidad insistente de palabras y argumentos que fueron colocados hace tiempo en el desván de las preguntas, tengan alguna significación. La permanencia de un asunto cancelado siempre quiere decir algo; al menos alude a una puerta inclinada a cerrarse en falso (García Montero, 2003: 11).

Viene al caso esta consideración porque, pese a las innegables prevenciones y rechazos, bostezos y cansancio, la revitalización del compromiso en la poesía española de las últimas décadas ha ido convirtiéndose en una realidad poco discutible. La reapertura del debate en torno a este problema y su desarticulación como tabú, después de un largo tiempo de descrédito de cualquier tentativa de planteamiento "responsable", han venido a restañar la fractura instaurada entre "lo poético" y "lo político" y a poner de notable actualidad la reivindicación de la funcionalidad crítica de la escritura. Por citar unos pocos datos más o menos recientes, que precipitan su acaecimiento a medida que nos aproximamos a la fecha de hoy, en 1994 la llamada Unión de Escritores del País Valenciano lanzaba un manifiesto proclamando su posición crítica ante determinadas estéticas legitimadoras de la cultura establecida (Ángeles et alii, 1994: 115-116),

\footnotetext{
${ }^{1}$ Nota de los editores: El presente artículo es un extracto del ensayo de Araceli Iravedra publicado como "Estudio preliminar" a su libro El compromiso después del compromiso. Poesía, democracia y globalización (poéticas 1980-2005) (Madrid: UNED, 2010) (Iravedra, 2010: 13-106). Transcribimos aquí las páginas 15-24 y 82-91. El texto original y la bibliografía han sido adaptados a las normas Kamchatka. Revista de análisis cultural.
} 
y en el ciclo "Poesía y conflicto" abordaba la discusión en torno a las relaciones entre ideología, escritura y subversión (Alicia Bajo Cero, 1997: 17). En 1997, un sector de estos poetas escondido tras la seña de Alicia Bajo Cero se enfrentaba en su ensayo Poesía y poder al discurso hegemónico de la poesía de la experiencia -canalizador, a su entender, de la ideología dominante-, y proponía la insumisión ideológica como camino viable para una práctica transformadora de visiones de mundo. En 1998, la editorial DVD publicaba una antología -Feroces- que, bajo el subtítulo de Radicales, marginales y heterodoxos, reunía un conjunto de voces poéticas situadas entre la voluntad radical de compromiso "resistente" y la rebeldía individualista más o menos iconoclasta y marginal. En 1999 tenía lugar en Moguer el primer encuentro anual de poetas que, bajo el marbete diferenciador de Voces del Extremo, convocaría desde entonces a un variado elenco de nombres hermanados por una concepción de la escritura como práctica radicalmente política orientada a combatir los supuestos del neoliberalismo. En abril de 2001, la revista Poesía en el campus dedicaba su entrega número 49 a responder a la pregunta formulada en el título _“¿Todavía hay compromiso? Poesía y globalización”-, e incorporaba una antología que venía a ilustrar la cuota de presencia que gozaba por entonces esta postura lírica. En la primavera de 2002 se celebraba en Madrid la primera edición del llamado Foro Social de las Artes, que, a través del debate en torno a núcleos de reflexión sobre las relaciones entre estética y política, buscaba "reconstruir la tradición crítica y antagonista que ha vertebrado el siglo XX" con el fin de "convertirla en energía para la producción artística de nuestros días"2. "Los compromisos de la poesía" es el título del número monográfico que la revista Ínsula consagra, a finales de 2002 (671-672, noviembre-diciembre), a revisar las manifestaciones de este fenómeno en el último cuarto del siglo XX, con una encuesta a más de treinta poetas, críticos y editores que detecta en la poesía española una plural renovación del compromiso con "lo público". Antes de que transcurra un año, la editorial Visor acoge, bajo el lema albertiano Hace falta estar ciego (y el subtítulo "Poéticas del compromiso para el siglo XXI"), un conjunto de reflexiones de poetas muy dispares sobre la pertinencia y el sentido del compromiso literario, un asunto que -a juicio de los editores- parece hoy "más oportuno que nunca" (Mariscal y Pardo, 2003: 11). Casi al mismo tiempo, la entrega de 2003 de la revista Zurgai presenta, con el título "Poesía de la conciencia", a una treintena de voces de la actual poesía que se afirman en la voluntad de intervenir, desde una escritura "utópica" y "a la contra", en la problemática de un mundo "de marcadas desigualdades, provisionalidad y cinismo" (Zurgai, 2003: 4). Como evento más accidental (menos significativo, por ello), ya en 2004 el atentado terrorista del 11 de marzo en Madrid reúne a unos doscientos poetas en torno a dos libros -Madrid, once de maryo. Poemas para el recuerdo y 11-M: Poemas contra el olvido- que se comprometen con el dolor y reivindican la libertad y el mestizaje contra un clima social de fundamentalismos e intolerancia. Pero también en este año ven la luz sendos conjuntos de poemas, Poemas para cruzar el desierto y Poesía pasión: doce jóvenes poetas españoles, que se dicen orientados no tanto a "cantar estados de ánimo como a lograr estados de conciencia" (Sierra, 2004), y se presentan como aldabonazos en "un tiempo en que la poesía parece haber abdicado de toda rebelión” (Moga, 2004). Por fin, en el año 2005, la editorial sevillana Libros de la Herida

\footnotetext{
2 El programa y el texto de la convocatoria fueron difundidos en la página web del llamado Manual de Lecturas Rápidas para la Supervivencia.
} 
pone a andar su colección "Poesía en Resistencia", concebida como una biblioteca de "libros de poemas para pensar el mundo"3.

Se diría que el discurso valedor de la utilidad política y social de la poesía, que, con algunas notorias excepciones, comenzó desenvolviéndose por circuitos marginales, va dejando ya de hacerlo; o, cuando menos, son esos circuitos demasiado numerosos como para permanecer discretos, y va haciendo su presencia cada vez más ruido. Claro que la apelación al papel de la poesía como eje corrector de realidades y valores no es una postura generalizada; ya se ha sugerido que las suspicacias hacia formas de escritura sospechosas de veleidades críticas no han dejado de hacerse notar, apercibido como está nuestro parnaso poético contra los errores y excesos del socialrealismo de posguerra. Pero frente a quienes han insistido en denunciar la frivolidad, la integración complaciente y el cinismo social y político como notas definitorias de nuestra poesía reciente 4 (apuntando, por lo común, al paradigma dominante de la poesía de la experiencia), parecen multiplicarse las voces que se alzan para reclamar a la escritura su cuota de responsabilidad ética o social. Incluso el modelo comunicativo de la corriente figurativa, en su voluntad de adecuación a la realidad inmediata, ha derivado en no pocas ocasiones hacia un discurso de irisaciones cívicas: sin falta de invocar ahora las implicaciones críticas del "realismo singular" de Luis García Montero, o la "épica subjetiva" de sus compañeros de viaje en "la otra sentimentalidad", pensamos en un generalizado ensanchamiento del horizonte temático, que supera la introspección sentimental propugnada por las primeras manifestaciones de la tendencia,

\footnotetext{
${ }_{3}^{3}$ Fuera del marco cronológico que acotan estas páginas, y mientras aguardan su turno para ser editadas, no remiten los síntomas de esta intensificación de la voluntad crítica: en 2006, y bajo el título Escrituras del desconcierto: el imaginario creativo del siglo XXI, Virgilio Tortosa reúne un conjunto de reflexiones acerca de las posibilidades y eficacia de prácticas artísticas no canónicas en su pretensión de construir alternativas a los escenarios del presente; en 2007 ven la luz los volúmenes antológicos Once poetas críticos en la poesía española reciente y Once poéticas críticas, a cargo de Enrique Falcón, que presenta algunas de las búsquedas más significativas en una "literatura de voluntad crítica y pulso resistente" (Falcón, 2007: 8) y acompaña estos proyectos editoriales con la fundación del sitio web La singladura de los once; y en este mismo año, Tierradenadie Ediciones lanza una obra colectiva, La (re)conquista de la realidad: la novela, la poesía y el teatro del siglo presente, que, bajo la coordinación de Matías Escalera, reivindica la necesidad de una literatura ocupada en desvelar "la realidad histórica, material, política, social, simbólica y económica" del mundo presente y en codificar artísticamente "los procesos de sumisión y de dominación a partir de los cuales se constituyen esas realidades" (Escalera, 2007: 8).

4 Véase, por ejemplo, el diagnóstico de Jaime Siles, para quien los poetas de la "generación del 80" no se sienten incómodos en la sociedad y con la sociedad, "sino integrados, complacientes y complacidos. Por eso, la de los 80 vuelve a ser una poesía integrada en su mundo y arraigada en su situación [...] Por eso no hacen poesía de evasión como hicieron los novísimos- ni de crítica -como el 50 sí la hizo-, sino de entendimiento, de aclimatación y -a veces: muy pocas- de interpretación. La nueva poesía, por lo general y con muy pocas excepciones [...] renuncia a criticar el mundo; evita, en la medida en que puede, el interpretarlo; y se conforma -que no es poco- con vivirlo" (Siles, 1991); de Santos Alonso, quien observa en la mayor parte de la producción poética de fin de siglo una absoluta desconexión con la realidad y con las inquietudes de los lectores, "de manera que los poetas parecen mirarse únicamente el ombligo como centro del mundo [...] Ahora los poetas no son ni disidentes ni conflictivos, sino narcisistas, autosuficientes y frívolos" (VVAA, 1994: 14); o de Rafael Conte: "como lo social ya no cotiza en la bolsa de las palabras, la sociedad ha desaparecido del horizonte" (VVAA, 1994: 15).
} 
y favorece la reflexión y la crítica sobre ciertos aspectos de la arena de "lo público" que habían sido relegados de la escena costumbrista posmoderna 5 .

Con todo, no será el objeto de estas páginas el examen de un discurso lírico ocasionalmente escorado hacia la esfera de "lo civil", que puede integrarse en el poema como uno entre otros de los desvelos temáticos de su creador: un discurso lírico, en suma, que se piensa solo "circunstancialmente (no esencialmente) o inevitablemente (casi por compromiso)" involucrado en la realidad histórica (García, 2006: 27); más bien, se trata de considerar un conjunto de soportes teóricos, sustentadores de otros tantos modelos poéticos, que reconocen abiertamente su naturaleza política $\mathrm{o}$, cuando menos, aceptan su articulación radical con la sociedad y la historia y la difuminación de los contornos de lo privado y lo público. Precisamente unas palabras de Miguel Ángel García parafraseando las tesis de Juan Carlos Rodríguez han sido convocadas por un amplio sector de estos poetas políticos en función de síntesis clarificadora de sus posiciones de fondo, enfrentadas al inconsciente artístico imperante por reivindicar ese anclaje forzoso en la historia. Valgan, pues, como declaración de principios comunes:

[Nuestro inconsciente ideológico/artístico termina incurriendo en] las mitologías del género poético $[\ldots]$ la poesía como discurso trascendental, enmarañado en las redes tejidas por la estética kantiana y la ideología burguesa clásica a partir de lo puro/lo impuro, la forma/los contenidos, lo inútil/lo útil, lo privado/lo público. Como si la poesía, en tanto que libre expresión de la intimidad más privada del sujeto moderno y supuestamente libre, solo pudiera vivir en los primeros términos de las dicotomías mencionadas y se asfixiara en los segundos; y al mismo tiempo como si la decisión del compromiso [...] dependiera de la responsabilidad/irresponsabilidad moral del escritor y no se situara más allá de su voluntad individual [...] nadie se encuentra descomprometido (aunque diga no creer en el compromiso) puesto que nadie escribe desde el vacío sino desde un lleno histórico radical, desde un inconsciente ideológico sobre sí mismo, el mundo y la escritura (VVAA, 2008: 18).

\section{DEL PLACER PRIVADO AL VÍNCULO PÚBLICO}

Pero la eclosión de estas prácticas poéticas, sea cual sea el inconsciente ideológico/artístico que las sustenta, no podría explicarse convenientemente si no es en el contexto de un nuevo clima estético que hace posible y hasta impulsa una voluntad de implicación dinámica en los proyectos colectivos. Es verdad que el relativismo y la condición escéptica concordantes con el pensamiento posmoderno no favorecen los entusiasmos excesivos ni colaboran en la formulación de afirmaciones rotundas en torno a las posibilidades de la poesía como instrumento útil al cuerpo social. Sin embargo, la primera generación de poetas de la democracia comenzó por cuestionarse su sentido en un sistema social que cada vez parecía prescindir más de ellos, y expresó reiteradamente su preocupación ante el acusado divorcio que, a juzgar por el escaso número de consumidores, la escritura iba mostrando respecto del mundo contemporáneo. Era un

\footnotetext{
5 Cfr. el reciente estudio de Luis Bagué Quílez Poesía en pie de paz, cuyas páginas demuestran que, ya a finales de la década de los ochenta, "muchas vertientes del compromiso (neocostumbrismo, sátira sociopolítica, ironía marginal y acanallada), eran consecuencia de las sucesivas derivaciones de la poesía de la experiencia” (Bagué Quílez, 2006: 29). Ya bien entrado el nuevo siglo, el mismo autor constata que la orientación de cierta lírica experiencial, invadiendo parcelas antes reservadas a tendencias aledañas o antitéticas, "promueve un compromiso posmoderno con los reciclajes de la ideología, las injusticias sociales o los desequilibrios del poder” (Bagué Quílez, 2008: 69).
} 
elemento diferencial respecto de la actitud de los novísimos, a quienes no pareció inquietar en absoluto este divorcio: si su poesía deliberadamente "festiva, intrascendente, divertida e inútil” (Cuenca, 1980: 250) exhibía con orgullo su condición gratuita, elitista y marginal, la hornada poética siguiente mostró, en cambio, una verdadera voluntad de recuperar el interés del público lector, de soldar la fractura instaurada entre poesía y sociedad y de trabajar en la búsqueda de una respuesta a las necesidades y demandas que esta última parecía solicitar.

Claro que el pacto de normalización que acompañó a nuestra transición democrática no fue un buen aliado de la revitalización del compromiso. Pues, según ha analizado Juan Carlos Rodríguez, esta normalización resulta inseparable de la desustancialización de la política que se aprecia en los años setenta y sobre todo en los ochenta ("política y filosofía se desustancializaban para convertirse en vida normal" [Rodríguez, 1999: 265]), y que implica hablar de la famosa muerte de las ideologías en el sentido de lenguajes políticos. Algo que, por otro lado, ocurría no mucho después de que primero en América y luego en Europa comenzara a difundirse la idea del fin de la modernidad, de su historia y de sus utopías constitutivas. Precisamente como un síntoma de la desconfianza posmoderna en los metarrelatos de la modernidad, la crítica ha venido aceptando para la que algunos ya han llamado "poesía de la socialdemocracia" (Salvador, 2003: 228) un generalizado descrédito de las utopías. Juan José Lanz ha contextualizado el fenómeno en el devenir de los sucesos históricos y ha explicado que, tras el fracaso de los sueños del mayo del 68 -hito que pone fin a todas las revueltas organizadas-, solo cabía la posibilidad de la no-acción, la revalorización del espacio individual que no se sacrificaría a ningún ideal colectivo, el retorno, en fin, al ámbito de lo privado, que se defendía como único margen de libertad que el individuo puede conquistar para sí. La renuncia a las utopías sociales se efectuaba entonces en nombre de la aspiración más modesta a la confirmación de las libertades individuales, a la salvaguarda de un rostro propio frente a las dinámicas de homologación, en la conciencia, por lo demás, de que "sólo transformando el ámbito del comportamiento privado se lograr[ía] la transformación del sistema" (Lanz, 1996: 28). Este planteamiento definió la actitud más común del sujeto de la poesía de la experiencia, corriente que desde el segundo lustro de los años ochenta se extendería como una gran mancha de aceite sobre el mapa poético español.

Sin embargo, la renuncia a las utopías sociales, y el intento consiguiente de reconquista del ámbito privado, no se relacionan necesariamente con el conformismo ni con un desconocimiento de la realidad pública. De hecho, clausurados el evasionismo artístico y la presunta indiferencia ética que singularizaron a las poéticas novísimas ${ }^{6}$, no resulta difícil detectar, a lo largo de los años ochenta y noventa, la creciente presencia y el renovado prestigio de una concepción de la escritura como posicionamiento moral ante la realidad. Se diría, incluso, que un cierto voluntarismo anima no pocas veces unas declaraciones de principios que, a la postre, no siempre se avienen con las prácticas poéticas de quienes las formulan (basta con revisar el número monográfico que la revista Ínsula consagra en enero de 1994 a tomar "Los pulsos del verso"). Y quienes postulan el restablecimiento de la función moral de la literatura, o quienes reclaman las deudas del poeta con la historia, no son solo voces provenientes de nuevas hornadas: a ellos se suman de manera sintomática autores tan supuestamente alejados de estas posiciones como

\footnotetext{
6 Para la revisión de esta cuestión problemática, véase el trabajo de Juan José Lanz “Himnos del tiempo de las barricadas': sobre el compromiso en los poetas novísimos" (Lanz, 2002: 8-13).
} 
algunos viejos novísimos7. Por ejemplo, Luis Alberto de Cuenca, que había evocado la temprana afición generacional por una poesía frívola e inútil (1980: 250), defendía en 1992 la absoluta legitimidad de una "poesía útil" que reconocía en algunas manifestaciones de entonces, y aplaudía también aquella poesía social de posguerra que entroncaba de modo directo, en su análisis, con el concepto ilustrado de utilitas (VVAA, 1993: 34); o -más radicalmente- Jaime Siles, reflexionando por esas mismas fechas sobre las posibilidades de la poesía frente a los retos del nuevo siglo, proponía un "compromiso con la historicidad" y apelaba a la "responsabilidad individual, colectiva y ética, que el poeta debe asumir en su tiempo histórico", constituyéndose en "eje corrector del sistema político, económico, social, etc. en que le toca vivir" (Siles, 1993: 141 y 152). La dinámica cíclica que rige los procesos culturales había promovido, sin duda, una alteración en el sistema de valores poéticos vigente. Por lo pronto, había sido necesario ese paulatino desplazamiento "del culturalismo a la vida" que, según diagnosticara en 1992 Miguel GarcíaPosada, venía acusando la poesía española en los últimos quince años (1993: 18), y que Leopoldo de Luis ya concebía como caldo de cultivo imprescindible para cualquier expresión poética de expectativas civiles (1969: 28).

Por otra parte, del señalado descrédito de las utopías habría que salvar desde el comienzo importantes excepciones. Con el inicio de la normalización democrática, el proyecto de "la otra sentimentalidad" (por cierto, intrínsecamente ligado a la recuperación de una nueva individualidad situada en el espacio de la historia) reabría el debate sobre el compromiso poético desde presupuestos radicalmente marxistas. Y sucediéndole, en tiempos más recientes, otras propuestas acuden a complementar, matizar o discutir los planteamientos del grupo granadino y sus derivaciones en el discurso experiencial de Luis García Montero: la "poesía practicable" de Jorge Riechmann, las "prácticas literarias del conflicto" de la Unión de Escritores del País Valenciano, la "poesía de la conciencia" de las onubenses Voces del Extremo... confluyen en una actitud de beligerancia frente al orden establecido, y se inscriben en un proyecto revolucionario que busca la emancipación de los imperativos del sistema. Para unos y otros, el desmoronamiento del régimen franquista no podía alentar el abandono de la lucha ideológica en el escenario colectivo. Por un lado, la conquista de la democracia parlamentaria con su alternancia de partidos, si había traído la libertad política, continuaba sin ofrecer respuesta a los desequilibrios económicos, y tampoco se mostraba en consecuencia como un modelo apto para instaurar la reconciliación y la fraternidad social. Por otro lado, la caída del socialismo real en Europa y el decretado fin de la historia parecían dejar al planeta en las manos únicas de un capitalismo neoliberal de consecuencias sociales nefastas, hábilmente maquillado bajo una proyección demasiado ilusoria -la "sociedad del bienestar"- que procuraba a este modelo globalizado la aquiescencia expresa o tácita también de quienes lo padecían. Así pues, si por lo que se refiere a España la muerte del dictador y la salida del franquismo no bastaban para justificar el silencio de la clase intelectual ante la historia, por lo que se refiere al mundo, tampoco la paz armada ni los excesos de una globalización económica despreocupada de sus consecuencias sociales o

\footnotetext{
7 Insistimos, con todo, en la necesidad de un replanteamiento de este asunto pendiente, capaz de explicar, por ejemplo, declaraciones tan aparentemente paradójicas como esta de Pere Gimferrer, que ya en 1970 contradice la lectura en clave no-comprometida de las poéticas novísimas: “Toda poesía que no persiga la contravención expresa o tácita del sistema represivo de la sociedad debe ser considerada como cómplice de este sistema" (Gimferrer, 1990: 27).
} 
medioambientales podían ya sostener, a los ojos de estos y otros autores, el repliegue del poeta a sus galerías interiores ni la idea de la literatura como exclusivo "placer privado" (Mainer, 1994), asentada en nuestras letras con el afianzamiento de la democracia.

En este contexto histórico y estético convergen modos muy dispares de encarar y resolver las relaciones entre poesía e historia, ideología o política. Aunque compartan una suma de constantes fruto de la necesaria adecuación a las nuevas circunstancias (políticas, económicas, culturales, poéticas), las propuestas que intervienen en esta reedición del compromiso no promueven un discurso lírico monocorde: más allá de la renovación inevitable de la cartografía temática, se trata también -y sobre todo- de la actualización de un modelo expresivo que suele mostrar su base común allí donde establece su fisura con la tradición histórica más inmediata, o mejor, frente a ciertas claves y postulados de la poesía social de los años cincuenta.

\section{$[\ldots]^{8}$}

\section{EL COMPROMISO DESPUÉS DEL COMPROMISO (UNA RECAPITULACIÓN)}

El examen contrastado de estas siete propuestas ${ }^{9}$ en liza revalida y nos conduce a rescatar una de nuestras afirmaciones iniciales: no es homogénea la relectura del compromiso efectuada en el contexto poético de la democracia española. Sin embargo, no hay tampoco duda sobre el proceso de resituación que han experimentado los nuevos discursos críticos, sobre la visible renovación de su horizonte especulativo y de sus ideales formales y temáticos, en virtud de su adecuación al actual mapa político y a la esfera cultural e ideológica de la posmodernidad. Y es en este reajuste de una noción de la escritura que adapta su reflexión a las incidencias del presente, y su enunciación a modelos expresivos de mayor complejidad y eficacia, donde identificamos algunas constantes que permiten hablar de un compromiso después del compromiso: en la era de la historia después de la historia, también esta instancia se renueva rompiendo con algunas de sus claves más arraigadas, aquellas que encuentran su emblema en la poética del realismo socialista y en la poesía social de los años cincuenta.

Por descontado, las circunstancias socio-políticas que separan nuestra posguerra del contexto que ha traído la nueva poesía crítica explican la presencia de diferentes contenidos y el desvío de la denuncia hacia ámbitos inéditos, sustancialmente distintos a los que atravesaban la poesía social de la dictadura franquista. El entonces concurrido "tema de España" se revitaliza

\footnotetext{
8 Nota de los editores: Tras la transcripción de las dos primeras secciones, realizaremos en este punto un salto hacia el final del texto original que ha sido consultado y aprobado por la autora. En este sentido, hemos preferido incluir los apartados que realizan un análisis panorámico de las problemáticas de la poesía en el periodo 1980-2005, con la finalidad de que pueda funcionar como herramienta "Para un debate previo", siguiendo el título de esta primera parte del monográfico. Por ello, no incluimos las secciones más específicas, cuya consulta en el libro original ofrece al lector un extenso y profundo estudio de buena parte de las corrientes poéticas que desde 1980 hasta 2005 se desarrollaron en España: "En busca de la otra sentimentalidad" (24-32), "Del sensismo a la poesía entrometida" (32-41), "La insurrección del desconsuelo" (41-50), "La provocación de lo real" (50-58), "Poesía y conflicto" (58-67), "Hacia una poesía de la conciencia" (67-74) y "Una experiencia singular" (74-82). Todos ellos en Iravedra (2010).

${ }^{9}$ Nota de los editores: Iravedra se refiere aquí a las siete propuestas detalladas en la nota anterior.
} 
ahora con nuevos matices, si bien, sobre todo, los contornos de la crítica se ensanchan hacia los conflictos internacionales y se orientan a la condena de la cultura militarista, las desigualdades planetarias que arroja un neoliberalismo socialmente insensible, las paradojas de la globalización económica y financiera, las catástrofes medioambientales que resultan también de la insensibilidad ecológica, el saldo dramático de la inmigración y de las conductas xenófobas... La denuncia alcanza asimismo a la esfera más estrictamente cotidiana del sujeto enunciador, y señala la perversa dominación ejercida sobre el individuo por la moral establecida, la violencia de la incomunicación en nuestros macroespacios urbanos, la miseria social apenas encubierta bajo la confortable sociedad del primer mundo y, en fin, las secuelas de las contradicciones profundas del capitalismo avanzado que interpelan diariamente la conciencia crítica del ciudadano de nuestros días.

Sin embargo, mucho antes que a los temas del poema, la especificidad de los nuevos discursos ha de atribuirse a una suma de a prioris teóricos, que guardan relación con las posturas ante el lenguaje, y que revelan una manifiesta alteración en los modos de pensar y escribir el compromiso. De ahí que ni una sola de las propuestas revisadas haya renunciado a desmarcarse, por un motivo u otro, de la tradición histórica inmediata; incluso sin ser poca la deuda que con ella contraen. De hecho, afirmar que la actual poesía crítica plantea los debates en torno al compromiso en un registro indiscutiblemente más maduro al del vate social de la posguerra no pasa de ser una verdad a medias que reclama precisiones y matices. No cabe ceder una vez más a la acostumbrada tentación de atribuir en bloque al realismo social los escollos en que tropiezan sus ejecuciones menos felices; y, por lo demás, no hay que soslayar una evolución interna que, principalmente a cargo de la generación del medio siglo (pero también de los mejores poetas socialrealistas), no tarda en introducir eficaces elementos correctores para la reconducción de un género que había ido perdiendo dignidad y prestigio por la repetición epigonal de modelos caducos. En realidad, no pocos rasgos de la poesía de ahora (síntesis de intimidad e historia, intensificación del componente individual, ironía desacralizadora, tono menor del discurso...) ya son una conquista del realismo crítico de los años sesenta, en manos del cual la poesía social más canónica pierde su candidez primera para asumir formas más complejas que buscan su acomodo a las nuevas necesidades históricas. Tómese, pues, en consideración esta advertencia, que invita a recibir con las debidas cautelas la gruesa recapitulación que sigue.

En la nueva poesía crítica, la aceptación de la entidad ideológica de la escritura, y de los vínculos intrínsecos entre poesía e historia, es un postulado clave para la superación de los planteamientos que tendían a situar el compromiso en el terreno de la decisión del autor; y conduce a la convicción de que todo discurso poético es, por encima o contra la voluntad del sujeto que habla, un discurso político. También se compromete quien se dice indiferente a los avatares de la historia, aunque termine por hacerlo -sujeto a los dictados de la ideología dominante- con los intereses del capitalismo y la moral burguesa. Se trata pues de no ceder, mediante la naturalización de un discurso lírico supuestamente neutral, a la trampa de un lenguaje "podrido" o "secuestrado" por la ideología del poder. Ahora bien, en el camino de la insubordinación ideológica los poetas tomarán opciones diversas. La otra sentimentalidad, que concede a los sentimientos una virtualidad revolucionaria, y así no discute los temas sino la manera de tratarlos, tiene que rechazar la "desfasada politización temática" (García Montero, 1993: 201) del realismo socialista y aplaudir, en cambio, la evolución de los poetas del cincuenta 
de "un compromiso político de ideales a una crítica de tono moral y autorreflexivo" (1993: 102). En cambio, la mayoría de las propuestas críticas encara la labor de insumisión ideológica a través de un asedio directo de los problemas colectivos, interpretando la elusión de tales asuntos como una forma de anuencia, y el desenmascaramiento de la representación "oficial" de la realidad mediante el testimonio o la denuncia como el camino más plausible para una práctica transformadora. Aunque haya también quien entienda (Riechmann, Alicia Bajo Cero) que sustraerse a la dictadura instrumental del lenguaje es el auténtico modo de alcanzar una palabra libre susceptible de escapar a los designios del poder, de cuestionar una concepción de la realidad que tiende a reproducirse mediante un lenguaje cuyos sentidos pertenecen al discurso establecido.

Pese al escepticismo de algunos dictámenes, las voces de la lírica reciente conservan la fe en la utilidad radical del género: la poesía no es inútil porque es un útil ideológico (Rodríguez, 1999: 125), y precisamente en esta cualidad descansa su potencia revolucionaria. La palabra poética incide en nuestro inconsciente y es en consecuencia susceptible de transformarlo, mediante la creación en el poema de un personaje responsable y reflexivo, que promueve una visión del mundo capaz de decir "otra moral" o de insinuar "otro ritmo posible". Sabe el poeta que la librada en el terreno de la ideología es la única batalla al alcance de la poesía, y aunque su funcionalidad no sea inmediata, hay que conocer su importancia, porque es en el pensamiento donde comienza la dominación. En palabras de Jorge Riechmann, un poema logrado constituye cuando menos una incitación a "quitarse las orejeras, salirse del carril, desuncirse de la noria, pararse al borde de la autopista y respirar" (1994: 31): esto es, a sustraernos a la tiranía del pensamiento establecido para invitarnos a repensar la realidad. Lo que se desmorona bajo esta concepción de la poesía como herramienta de lucha ideológica es el sentido positivista de la noción de utilidad abrazado por el realismo socialista: el poema no aspira a la resolución de crisis y conflictos, sino tan solo al entrenamiento en el "uso de razón crítica y de corazón libre" (García Montero, 1993: 236), a la resistencia frente a la moral instituida y el control de los mensajes ejercido desde el poder. A lo sumo, el poema se cumple en la denuncia como elemento perturbador, y de ahí que escaseen en estos discursos los imperativos o consignas movilizadores y las proyecciones hacia un futuro mítico, conforme al esquema canónico de la poesía social: frente a esta, la nueva poesía crítica rebaja su componente utópico. Desterradas las proclamas voluntaristas sobre la inmediatez instrumental de la palabra, se subraya la lenta fecundidad de un arte que, dispuesto a desenmascarar los espejismos de la realidad y constituirse en propuesta ética, despierte la conciencia crítica del lector frente a las leyes del pensamiento único.

Con el descrédito del alcance positivo de la escritura, ha desaparecido de los actuales compromisos el viejo sentido de misión, la condición salvífica y redentora que había conformado al yo heroico del realismo social10. Apoyándose en René Char -"el poeta tiene a lo más una tarea, pero no una misión"-, Jorge Riechmann toma explícitas distancias frente a la postura y los versos de un Gabriel Celaya: “Mientras haya en la tierra un solo hombre que cante / quedará una esperanza para todos nosotros' no son versos cerca de los cuales podamos acampar hoy" (Riechmann, 2001: 24). (Y, en efecto, una réplica semejante suscitaba en Antonio Orihuela la

\footnotetext{
10 No faltan, con todo, algunas reminiscencias: véase, por ejemplo, en la selección de textos, el artículo de Salustiano Martín en su epígrafe "Rescatar la rosa del lodazal teledirigido", donde apela a la restitución de los poetas a la república para contribuir -eso sí, "humildemente”- a la salvación colectiva (Martín, 2010: 287).
} 
consigna celayana). Esto tiene consecuencias en el terreno del lenguaje, pues conduce al abandono de la retórica altisonante y los acentos grandilocuentes en otro tiempo adoptados por el poeta-profeta: como ha reflexionado Jon Juaristi, asumida la pérdida del lugar social del poeta, el desplazamiento de la poesía como lugar central de la cultura y la consiguiente merma de centralidad en las estructuras de poder, el discurso se torna necesariamente melancólico, y la ironía es el único lenguaje posible que le queda a la melancolía (Juaristi 1999: 77 y 111).

La configuración del sujeto poético es en los nuevos discursos críticos otra de los principales espacios de quiebra con la poesía social de los años cincuenta. No solo porque el mencionado yo heroico se torne persona normal, o bien un antihéroe o yo marginal; también porque, frente a las pretensiones de objetividad del discurso socialrealista, que en busca de la representación del sujeto colectivo procuraba la exclusión de toda injerencia subjetiva del poeta, esta poesía acusa un acendramiento de la perspectiva individual, y promueve la indagación en lo social desde un yo de alcance existencial. No en vano la familia de la otra sentimentalidad -en sintonía con los postulados del "realismo crítico"-impugnó los límites estéticos de un realismo socialista que proscribió el derecho a la intimidad y a la diferencia en nombre de la sacralización homogeneizadora de lo colectivo. La convicción de que nada se escribe sino a través de la individualidad, reiterada por García Montero, resulta expresamente rubricada por Fernando Beltrán y por Jorge Riechmann, partidarios ambos de una escritura desde la experiencia. (Jorge Riechmann, una vez más, ha señalado la pretensión de sustituir la experiencia de otros como "el pecado original de la poesía llamada social: la raíz común de sus flaquezas estéticas y éticas" [2001: 24]). De ahí que el sujeto enunciador del poema exhiba a menudo un marcado talante autobiográfico, aunque aspire a representar a su vez las inquietudes y desvelos de un "hombre de la calle"; la fatal intromisión de lo colectivo en la existencia cotidiana del sujeto promueve su implicación ética en la realidad y su voluntad de compromiso.

Por último, la retórica que reproduce el compromiso contemporáneo presenta una apariencia poliédrica. Comparte por lo general con su tradición inmediata una firme vocación antiesteticista -no falta siquiera quien suscriba el célebre aserto celayano: "Escribiría un poema perfecto / si no fuera indecente hacerlo en estos tiempos"11. Gobernados por una voluntad de socialización de la poesía, sus artífices tratan de acertar con una fórmula expresiva capaz de conectar con el lector común; de ahí el recurso muy frecuente al paradigma realista, incluso a un empleo descarnadamente enunciativo del lenguaje. En otro sentido, tanto la exigencia de veracidad como el designio de provocación, de transgresión de los límites de lo correcto, conducen a algunos (Wolfe, González, Orta) al uso de un registro en extremo desaliñado y vulgar, más allá del prosaísmo, en ocasiones antipoético, donde la depauperación léxica resultante, a veces justificada por el clima de la historia, no siempre se resuelve en una fórmula estéticamente feliz. Tampoco lo hace en los momentos peores un excluyente imperativo de comunicación que se impone como prioridad absoluta sobre la voluntad de indagación poética, y que arroja como saldo un mensaje precipitado hacia la prosa, no solo formalmente descuidado sino significativamente unívoco, más próximo al panfleto que al poema y en el borde de la poesía

\footnotetext{
11 Para un análisis en detalle de esta "retórica antirretórica", véase el trabajo de Leopoldo Sánchez Torre "De lo real y sus retóricas: realismo y antipoesía en las nuevas poéticas del compromiso" (2002: 49-53).
} 
doctrinaria, de tesis previa al texto, propia del realismo social más fallido. Aunque no puede negarse que el severo discurso doctrinal a que condujo la disciplina socialrealista tiende a sortearse hoy (en la estela de los autores del cincuenta) por el recurso a la ironía o al humor como mecanismos desacralizadores, propiciadores de un distanciamiento que descarga de patetismo y de rigores dogmáticos la palabra poética, entregada más bien a un testimonialismo socioexistencial matizado por el escepticismo y el desengaño.

Por lo demás, la retórica del nuevo compromiso incorpora con frecuencia un enriquecimiento de la dimensión estética del texto, cuando el discurso coloquial resulta sometido a diversos mecanismos de dislocación (rítmica, sintáctica, semántica) potenciadores de la ambigüedad poética. Buscando su extremo, el racionalismo clásico del discurso realista puede verse suplantado por un discurso de andamiaje surrealista o, cuando menos, contaminado por una técnica irracionalista (Beltrán, Riechmann, Falcón, Méndez Rubio) que sirve a la voluntad más fiel de representación de una realidad conflictiva, al intento de salvar la rigidez interpretativa de la enunciación y potenciar la creatividad crítica en el proceso de lectura, o de rebelarse ante los parámetros de un lenguaje funcional que se percibe colonizado por el poder. En general, se detecta en un sector de las nuevas propuestas la indagación de un arte revolucionario que rompa con el molde realista para reformularse a la luz de los discursos de vanguardia, desafiando los riesgos de marginalidad a que aboca la oclusión significante y eligiendo la desarticulación de la convención lingüística y la liberación formal como táctica de subversión. Desde esta perspectiva, se aprecia en el canon realista un efecto anestesiante, en la idea de que cualquier acción política de ruptura ha de pasar por una conciencia crítica del código lingüístico; y frente a la tiranía paralizante de lo Real, la alternativa retórica es la búsqueda de una palabra cuya fuerza libertaria se funda en su radical insumisión a la servidumbre referencial. Una vuelta de tuerca que aproxima el nuevo compromiso a algunas propuestas estéticas de la tradicionalmente denostada (desde estas latitudes poéticas) práctica novísima, para la que el carácter político de la poesía se jugaba en su capacidad de crítica y construcción de lenguajes ${ }^{12}$.

En su breve introducción a los Once poetas críticos en la poesía española reciente, Enrique Falcón sintetiza con notable exactitud ( $\mathrm{y}$ aun a su pesar, pues no está en su voluntad contar con los discursos de afiliación experiencial ${ }^{13}$ ) la pluralidad de registros ensayados por esta nueva literatura de latido crítico, que oscila entre el designio de ruptura y transgresión del lenguaje y otra clase de retóricas "más transparentes" en las que una noción "plana" de realismo podría con todo "resultar agujereada" en más de un aspecto. Concluye, además, su reflexión estableciendo como denominador común el postulado tal vez central entre los que apuntalan este compromiso renovado:

\footnotetext{
12 No hay que olvidar, con todo, que ya en la posguerra contamos con precedentes aislados de esta aproximación al compromiso desde una escritura de corte experimental (caso, por ejemplo, de un Miguel Labordeta). Para la cuestión del compromiso en los poetas novísimos, de nuevo remitimos al trabajo de Juan José Lanz (2002: 8-13).

13 Jorge Riechmann, Daniel Bellón, Isabel Pérez Montalbán, David González, Antonio Orihuela, Antonio Méndez Rubio, Enrique Falcón, Miguel Ángel García Argüez, David Franco Monthiel, David Eloy Rodríguez y José María Gómez Valero son los once poetas críticos antologados por Falcón, para quien las prácticas estéticas de Luis García Montero y sus compañeros de viaje quedarían del lado de las "escrituras literarias ideológicamente tranquilizantes" (Falcón, 2007: 10).
} 
Los registros aquí experimentados [...] son plurales y se mueven del objetivismo documental a la deriva libertaria, de la poesía de la conciencia al torrencialismo irracional, del vanguardismo crítico al realismo más contundente, del relato narrativo al discurso atomizado, de la historia de la memoria al ejercicio de la ironía, del impulso visionario a las prácticas saludables de la lucidez, y -en fin- de las tácticas disidentes de la sugestión a las estrategias materialistas del extrañamiento. De ninguna de estas opciones, sin embargo, cabría deducir que "lo personal" y "lo político" pudieran constituirse como esferas separadas, por mucho que el discurso neoliberal imponga falsamente en nuestro tiempo una brutal separación entre lo público y lo privado (Falcón, 2007: 12).

Hace ya unos quince años que Luis Antonio de Villena, al tiempo que dictaminaba el epigonismo de la tendencia que llamaba de "tradición clásica" -expresión que pretendía dar "historia y amplitud" al concepto de poesía de la experiencia-, especulaba sobre las vías posibles de regeneración y aventuraba el florecimiento de una "nueva poesía social" o, cuando menos, una poesía de mirada más colectiva (Villena, 1992: 33). Hoy podemos afirmar que el rechazo de esta etiqueta por algunos adalides del actual compromiso es, por lo pronto, un síntoma del espíritu de novedad con que en efecto se encara hoy esta tarea; novedad en la que no conviene dejar de insistir, pues su examen nos muestra la esencial transformación de una noción de la escritura muy apegada en la mentalidad de los lectores a las prácticas socialrealistas de la dictadura. En cualquier caso, la profecía de Villena hace fortuna, sobre todo, en los años noventa del pasado siglo, cuando llega el ensañamiento por varios frentes contra una práctica de la poesía que ha conquistado un indiscutible lugar hegemónico, que señala el canon estético de su tiempo y que, en su conjunto, no formula su "ruptura interior" (Villena, 1997) mediante una voluntad de apertura a la historia ni el fortalecimiento de los vínculos con el hecho social. Por eso, salvo con algunas -muy notables- excepciones, tal y como anunciábamos al comienzo, los discursos poéticos del compromiso han tendido a desenvolverse por circuitos marginales. Así lo atestiguan las editoriales alternativas en que publican sus creadores (Germanía, Ateneo Obrero de Gijón, Icaria, Vitruvio, Línea de Fuego, Crecida...) y los significativos membretes que se autoimponen (Radicales, marginales y heterodoxos es el subtítulo de la muy citada antología Feroces; Voces del Extremo se autodenominan los protagonistas de los encuentros de Moguer). Sin embargo, su presencia creciente se hace ostensible no solo en el campo de la edición convencional, sino, también, a través de iniciativas promotoras de toda clase de foros -reales o virtuales- de discusión y encuentro. La labor del equipo crítico Alicia Bajo Cero y los proyectos de la Unión de Escritores del País Valenciano (hoy disuelta en el Foro Social de las Artes) se ven acompañados desde Madrid por la activa militancia del llamado Manual de Lecturas Rápidas para la Supervivencia, interesado en las "Prácticas comunistas y libertarias de la poesía y la literatura". Este "pasquín" literario promovido en sus comienzos por David Méndez y Álvaro Moreno no solo acoge en sus entregas periódicas, o a través del colectivo Material inflamable para manos incendiarias, las voces poéticas del extremo y del conflicto; además, articula un espacio digital con vocación de promover, contra la propiedad intelectual, la libre circulación de las ideas ("El mundo no es una mercancía. Las ideas tampoco") y sobre todo de constituirse, bajo el lema rimbaudiano "cambiar la vida" y a través de una palabra 
inquieta e incómoda, en "una ventana abierta contra toda anestesia"14. A la revista de literatura y política Mientras Tanto ("publicación de ciencias sociales" y clara orientación marxista con una sección fija de "Poesía practicable" -Riechmann al fondo) o a la surrealista Salamandra (órgano de "Intervención surrealista, Crítica de la vida cotidiana e Imaginación insurgente"), se unen la más reciente aunque ya clausurada Lunas Rojas ("revista de poesía civil" difundida a través de la red por Virgilio Tortosa, Enrique Falcón, José Luis Ángeles y Julia López de Briñas)15, la publicación malagueña La hamaca de lona (dirigida desde Madrid por Juan Antonio Mora) o la "revista crítica de las artes y el pensamiento" Youkali, editada por Tierradenadie Ediciones y también con su propio espacio web que da de nuevo voz a marginales y resistentes ${ }^{16}$. De hecho internet se convierte, para estas iniciativas, en una ventajosa y democrática vía de expansión e interrelación de unas corrientes de escritura con precarios medios para la difusión mediante el soporte convencional (denuncian ellos una interesada política de subvenciones que margina los discursos no conniventes con el discurso del poder), y así van tejiendo una suerte de infranet subterránea que, también en este ámbito, pugna por convertirse en alternativa al discurso preponderante del mercado. Y no faltan, por último, los cada vez más numerosos encuentros para la discusión en torno a este ejercicio de "Poesía en Resistencia" y la tradición contestataria de la práctica artística, promovidos periódicamente por diferentes colectivos poéticos y de agitación cultural desde Sevilla (La palabra Itinerante), Madrid (Grupo Surrealista de Madrid), Valencia (Foro Social de las Artes) o Huelva (cuyas Voces del Extremo ya han celebrado su novena edición).

"Después de década y media de poesía tranquila, tranquilizante y tranquilizada en España, ¿quién había predicho el regreso - para este inicio de siglo- de una poesía contra todo descanso extrema, con conciencia, para un mundo anestesiado?” (Falcón, 2010: 68). Era el diagnóstico reciente y entusiasta de Enrique Falcón, que de nuevo relegaba sin distingos al terreno de la autocomplacencia a las propuestas experienciales, aludidas bajo ese calificativo -"tranquila"- que, si remitía en su origen a los nexos de estas escrituras con la poética de Wordsworth, adquiría en el discurso del poeta "conflictivo" claras connotaciones de indolencia inhibitoria. Sea como sea, y pese a los enfrentamientos internos entre una palabra integrada que, desde el paradigma lírico todavía dominante, renovaba el compromiso con los proyectos colectivos, y una palabra extrema y marginal que conspira fuera de -y contra- la norma que gobierna las poéticas imperantes, una y otra colaboran desde un mismo frente de batalla (el territorio ideológico) en la elaboración precaria de respuestas, o siquiera de incómodas preguntas, ante las urgencias del espacio público y

\footnotetext{
${ }^{14} \mathrm{La}$ "Biblioteca virtual" de este sitio web, que ya difunde libremente más de 70 poemarios entre sus visitantes, aparece arropada por una elocuente cita de Jorge Riechmann -"El capital quiere hacernos creer que somos lo que vendemos. Pero somos lo que regalamos"-, y su editorial contiene esta advertencia que, de nuevo, y en estricta sintonía con Alicia Bajo Cero o las Voces del Extremo, contraviene la noción de copyright: "En definitiva, amigo lector, amigo escritor, todos los textos de esta sección contienen copyleft bajo Creative Commons, es decir, que QUEDA RIGUROSAMENTE ALENTADA LA REPRODUCCIÓN O DIFUSIÓN, total o parcial, de cualquiera de estas obras bajo cualquier medio, ya sea químico, mecánico, óptico, de grabación o fotocopia”. El desacuerdo teórico con la propiedad intelectual y con la instancia del autor justifica asimismo esta nota irónica de David Méndez a una selección de sus poemas en la revista Zurgai: "(Los textos que anteceden están sometidos estrictamente a copyleft. Pueden ser libremente copiados, reproducidos y distribuidos, así como alterados, recortados, completados, modificados y reelaborados siempre que ninguna de estas actividades genere beneficio económico ni individual y su producto esté sometido, a su vez, a este mismo copyleft)" (Méndez, 2003: 105).

15 Todos los números pueden encontrarse en el siguiente enlace.

16 A continuación, adjuntamos los enlaces correspondientes a La hamaca de lona y Youkali.
} 
el desfondamiento ideológico contemporáneo; y suponen, al fin, el correlato literario de los movimientos de agitación social y la creciente reflexión intelectual que, en el filo del milenio, han suscitado el nuevo escenario de la globalización, las contradicciones del capitalismo postindustrial, el imperio ideológico de los finalismos y la sociedad de las homologaciones de nuestra era posmoderna. 


\section{BIBLIOGRAFÍA}

Alicia Bajo Cero (1997). Poesía y poder. Valencia: Ediciones Bajo Cero.

ÁNGELES, José Luis et alii. "Manifiesto poético". Diablotexto 1 (1994): 115-116.

Bagué Quílez, Luis (2006). Poesia en pie de paz. Modos del compromiso hacia el tercer milenio. Valencia: Pre-Textos.

BAgué Quílez, Luis. "La poesía después de la poesía. Cartografías estéticas para el tercer milenio". Monteagudo. Revista de Literatura Española, Hispanoamericana y Teoría de la Literatura 13 (2008): 49-72.

CuencA, Luis Alberto de. “La generación del lenguaje”. Poesía 5-6 (1980): 245-251.

EsCALERA, Matías (2007). "El vacío abisal de una literatura sin realidad presente (ni pasada)". Esclaera, Matías (ed.). La (re)conquista de la realidad: la novela, la poesía y el teatro del siglo presente. Ciempozuelos: Tierradenadie Ediciones: 7-16.

FALCÓN, Enrique (ed.) (2007). Once poetas críticos en la poesía española reciente. Tenerife: Baile del Sol.

FALCÓN, Enrique (2010). Las prácticas literarias del conflicto (Registro de incidencias: 1991-2010). Madrid: La Oveja Roja.

GARCÍA, Miguel Ángel. "Y casi por compromiso. Consideraciones sobre poesía actual”. Paraíso. Revista de poesía 1 (2006): 25-35.

García Montero, Luis (1993). Confesiones poéticas. Granada: Diputación Provincial (Colección Maillot Amarillo).

García Montero, Luis (2003). "Poetas políticos y ejecutivos bohemios". MARISCAL, José M. y PARDO, Carlos (eds.). Hace falta estar ciego. Poéticas del compromiso para el siglo XXI. Madrid: Visor: 11-23.

GARCÍA-POSADA, Miguel (1993). "Del culturalismo a la vida". VVAA. Últimos veinte años de poesía española. Oviedo: Fundación Municipal de Cultura: 18-24.

Gimferrer, Pere (1990). "Poética”. MARTín PARdo, Enrique (ed.). Nueva poesía española (1970). Antología consolidada (1990). Madrid: Hiperión: 26-28.

IRAVEDRA, Araceli (2010). El compromiso después del compromiso. Poesía, democracia y globalización (poéticas 1980-2005). Madrid: UNED.

JuARISTI, Jon (1999). Sermo bumilis (Poesía y poéticas). Granada: Diputación Provincial (Colección Maillot Amarillo).

LANZ, Juan José. "La generación del ochenta. Límites históricos y socio-culturales". La Página 25-26 (1996): 17-29.

LANZ, Juan José. "Himnos del tiempo de las barricadas: sobre el compromiso en los poetas novísimos". Ínsula: revista de letras y ciencias humanas 671-672 (2002): 8-13.

LuIs, Leopoldo de (ed.) (1969). Poesía social. Antología (1939-1968). Madrid-Barcelona: Alfaguara. 
MAINER, José-Carlos (1994). "Poesía lírica, placer privado". MAINer, José-Carlos (ed.). De Postguerra (1951-1990). Barcelona: Crítica: 161-170.

Mariscal, José M. y PARdo, Carlos (eds.) (2003). Hace falta estar ciego. Poéticas del compromiso para el siglo XXI. Madrid: Visor.

MARTín, Salustiano (2010). "Democracia, ciudadanía y poesía de la conciencia crítica". Iravedra, Araceli (ed.). El compromiso después del compromiso. Poesía, democracia y globalización (poéticas 1980-2005). Madrid: UNED: 284-287.

MÉNDEZ, David. “Poemas”. Zurgai 30 (segunda etapa) (2003): 105-106.

MogA, Eduardo (ed.) (2004). Poesía pasión: doce jóvenes poetas españoles. Zaragoza: Libros del Innombrable.

MONTERO, Josu. "Breve génesis de la poesía política española actual: subversión lingüística y realismo crítico". Zurgai 30 (segunda etapa) (2003): 6-10.

RIECHMANN, Jorge. "El derrotado duerme en el campo de batalla". Ínsula: revista de letras y ciencias bumanas 565 (1994): 31-32.

Riechmann, Jorge. "Los próximos cien años (de la mano de Gabriel Celaya)". Poesía en el campus 49 (2001): 24-27.

Rodríguez, Juan Carlos (1999). Dichos y escritos. (Sobre "La otra sentimentalidad" y otros textos fechados de poética. Madrid: Hiperión.

SALVAdOR, Álvaro (2003). Letra pequeña. Granada: Los Cuadernos del Vigía.

SÁNCHEZ TORRE, Leopoldo. "De lo real y sus retóricas: realismo y antipoesía en las nuevas poéticas del compromiso". Insula: revista de letras y ciencias humanas 671-672 (2002): 49-53.

SIERRA, Ángel (ed.) (2004). Poemas para cruæar el desierto. Ribadesella: Línea de fuego.

SILES, Jaime. "Dinámica poética de la última década". Revista de Occidente 112-113 (1991): 149-169.

SILES, Jaime (1993). "La poesía ante el nuevo siglo: balance y posibilidades". VVAA. Propuestas poéticas para fin de siglo. Madrid: Fundación Cultural Banesto: 141-158.

VAllvey, Ángela (2000). "Peaje para el alba (Sobre la poesía de Jesús Munárriz)". MunÁrriz, Jesús (ed.). Peaje para el alba. Antología 1972-2000. Madrid: Hiperión: 7-24.

VillenA, Luis Antonio de (1992). "La respuesta clásica (El sesgo por la tradición en la última poesía española)". Villena, Luis Antonio de (ed.). Fin de siglo. El sesgo clásico en la última poesía española. Madrid: Visor: 7-34.

VILLENA, Luis Antonio de (1997). 10 menos 30. La ruptura interior en la poesía de la experiencia. Valencia: Pre-Textos.

VVAA (1993). Últimos veinte años de poesía española. Oviedo: Fundación Municipal de Cultura.

VVAA. "Encuesta a poetas, críticos y editores". Insula: revista de letras y ciencias humanas 565 (1994): $11-21$

VVAA (2008). Voces del Extremo: poesía y capitalismo. Moguer: Fundación Juan Ramón Jiménez.

ZURGAI, diciembre de 2003: "Poesía de la conciencia crítica". 